\title{
Escuela y tiempo libre
}

\section{"El tiempo libre y el tiempo para uno mismo han dejado de coincidir en la vida del hombre contemporáneo"} (Leif, 1992).

LUIS EDUARDO OSPINA LOZANO*

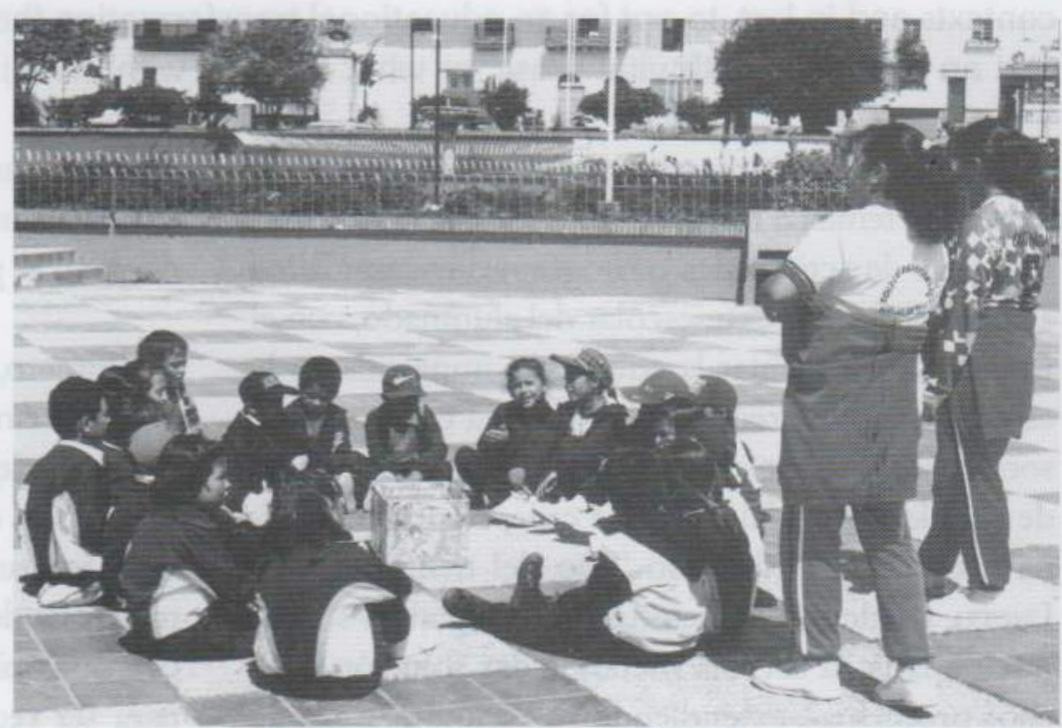

Por: Mario G. Loaiza Padilla

\section{Resumen}

\section{Q}

ste artículo merece ser iniciado con acto prudencial, pues las aclaraciones pertinentes, contribuyen a menguar el dolor en la herida tradicionalista y reducen la posibilidad de escándalo en quienes defienden los sistemas repeticionistas e instruccionistas, con visibles métodos de vigilancia y control, propios de la deshumanizada "educación" moderna. Lo aquí expuesto está implícito dentro de la teoría personalizada de la educación, que a lo sumo, es la única posibilidad educativa del ser humano. Pero la intención principal es invitar a la reflexión pedagógica; es decir, plegarnos sobre códigos educativos actuales y verificar la validez de los mismos en la formación personal. Se trata de confrontar contextos y, en últimas, optar por una transformación educativa que lleve al acto vocacional; es decir, a una educación con sentido vital, o lo que es igual, con significado y dirección existencial.

Fecha de recepción: octubre 15 de 2003 - Fecha de aceptación: octubre 30 de 2003

Palabras clave: tiempo, tiempo libre, escuela, libertad, persona humana, educación, actuación, juego, integralidad.

\section{Abstract}

This article deserves to be initiate with prudential act, because the pertinent explanations, contribute to decrease the pain in the traditionalist wound and they reduce the possibility scandal in those who defend the repetitive and introductory systems, with visible methods of surveillance and control,

* Profesor Departamento de Educación Física. Universidad Libre. Bogotá 
characteristic of the one dehumanized modern "education". The thing here exposed is implicit inside the personalized education theory that at most, it is the only educational possibility of the human being. But the main intention is to invite to the pedagogic reflection, that is to say, to bend on current educational codes and to verify the validity of the same ones in the personal formation. It is to confront contexts and in last, to opt for an educational transformation that takes to the vocational act; that is to say, an education with vital sense, or what is same, with meaning and existential direction.

Dentro del marco tradicional educativo puede tratarse el tema en forma sencilla. Se visualiza como una serie de actividades o programas encaminados a copar el tiempo extraescolar del alumnado, con el fin de complementar la educación impartida en la escuela, pues la preocupación de ésta como agente socializador, es meterle mano a toda la gama actual de problemas sociales, que se cree, surgen de alguna manera en el llamado "uso del tiempo libre". Luego, desde su intencionalidad adaptativa-socialdisciplinaria, la escuela pretende dar solución a dichos problemas, extendiendo su acción más allá de lo comúnmente otorgado en tiempo y espacio. Busca llegar hasta lo inexplorado (académicamente hablando), lo azaroso y caótico, donde se supone, se cuecen todos los vejámenes sociales por falta de una educación adecuada. Así, se da por hecho, que los jóvenes y niños, en ausencia del patrocinio escolar, soh incapaces de distribuir y gobernar su tiempo; entonces la escuela está llamada a poner orden bajo una concepción prefabricada del uso del tiempo libre.

Pero desde lo profundo de la conciencia docente cabe preguntar: ¿Es posible una educación para el uso del tiempo libre? ¿En realidad se trata de educar o de ocupar? ¿Si el niño es libre fuera de la escuela, cuál es su condición dentro de ella? ¿Qué papel juega la libertad en la educación del hombre? ¿Es posible diseñar y llevar a cabo un programa extraescolar para el uso del llamado "tiempo libre"? Desde el análisis y la reflexión conceptual, tocando de igual manera con la praxis educativa, es posible hallar respuestas a los interrogantes propuestos, esto requiere de búsqueda sistemática constante, esperándose como resultado, un mejor acercamiento al mundo educativo por redimensión del tema expuesto. En este sentido, hablar del uso del tiempo libre no es cuestión fácil, merece un trato acorde con la dignidad humana, situación que nos remite de forma inmediata a la esencia pedagógica del fenómeno y eso es precisamente el propósito de este escrito.

Primero, hay que reconocer que se trata de categorías netamente humanas e interrelacionadas; cuestión compleja que no puede ser abordada con sesgo verticalista de certidumbre y represión, ya que los seres humanos, como unidades personales, no tenemos nada definido con respecto al devenir de la propia vida, excepto, un arduo camino de perfección para ser recorrido día tras día. Somos organismos inconclusos pero con capacidad autoconstructora, tarea que, popularmente hablando, termina cuando nos ponen el "abrigo de palo".

De tal modo que no se pretende abordar el tema de manera simple y apurada. No implica un recetario de actividades extraescolares al amparo de intereses repetitivos transmisionistas. Tampoco es ampliación de la vida escolar y menos actividad académica del maestro en horarios y espacios aparte de la escuela, pues si hoy se afirma que existe divorcio entre lo escolar y la vida real cotidiana, porque la institución no ha bregado a articular su discurso con la dinámica cultural en que se halla situada, por ende lo único que podría hacer la escuela desde esta perspectiva, sería extender y perpetuar su función de manera simple y apurada. No hay intención entonces de exponer fórmulas salvadoras en torno al tema. No se persigue ampliar el "tejemaneje" escolar. No, definitivamente no es el objeto acceder académicamente a ese mundo azaroso con el fin de ordenarlo y curricularizarlo desde lo tradicional.

De otra parte y en lo que aquí concierne, cobra gran importancia y aplicabilidad la siguiente cita aristotélica: "De una manera investiga el ángulo recto el carpintero, y de otra el geómetra: el primero 
hasta donde pueda ser útil a su obra, en tanto que el segundo, contemplador de la verdad, considera su esencia y sus propiedades." (Aristóteles, 1994). De igual manera, en lo que atañe a la educación, el maestro debe investigar en la contemplación de la verdad y no quedarse en

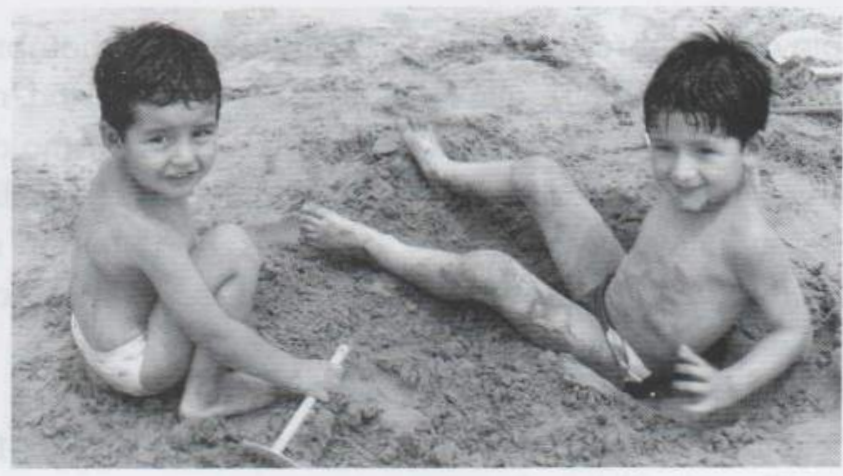

Por: Rafael Castañeda
Desde lo anterior se entiende, que el hombre, en tanto que humano, esta llamado a vivir y dejar vivir. Pero no es la vida entendida como movimiento de la materia... No es lo biológico lo que media. Es la vida en sentido espiritual. la utilidad instruccionista, de lo contrario su quehacer será superficial y carente de sentido humano, ya que instrucción y educación no son equivalentes.

Por tal razón, cuando en la educación colombiana se exigen unas acciones pedagógicas relacionadas con la educación para el uso del tiempo libre (Decreto 1860. Art. 14. Numeral 6), lo que se demanda, antes de cualquier programa de actividades, es una profundidad teórica y articulada de todos los conceptos involucrados (tiempo, libertad y educación) desde lo pedagógico y lo filosófico, con el fin de cimentar antropológicamente la acción educativa, en y desde el tema planteado, pues no es lo mismo obrar desde la sospecha que desde el estudio riguroso, analítico y reflexivo. "Debemos, por tanto, esforzarnos en ir hacia los principios atendiendo en cada caso a su naturaleza, y poner luego toda nuestra diligencia en definirlos correctamente, porque de gran momento son ellos para lo que de ahí se siga." (Aristóteles, 1994). He aquí la razón de ser del presente artículo.

\section{La finalidad educativa}

$\mathrm{El}$ análisis existencial ha dejado ver que el ser humano sólo se siente autorrealizado en la medida en que, a través de su vocación, encuentra sentido a la vida misma. Esto constituye el ser propio de lo humano, ya que encierra la razón de concretarse como persona; es decir, como alguien con situación, identidad y rol definido, de forma única e irremplazable. Es autorrealización, o sea, vida plena y dinámica en obediencia al llamado existencial.
La vida que eleva al hombre a la categoría de persona, que lo aprecia en su integralidad y lo considera totalmente unido al universo, con un destino inherente de autoconstrucción. Es por lo tanto ese tipo de vida que se hace irrenunciable porque lleva implícito el compromiso de llegar a ser. "Llamados a vivir, no tenemos otra elección inteligente que la de vivir! Y, vivir "bien", porque sólo a nosotros se nos da está posibilidad. ¡Nuestro llamado a la muerte sólo tendrá sentido después de la elección que hallamos hecho en favor de la vida!" (Zezinho, 1995: 23).

Ahora bien, cuando el hombre responde adecuadamente al llamado existencial, se presentan situaciones del estado autorrealizativo. A esto se le llama felicidad. Sobreviene un gran sentimiento de satisfacción por el deber cumplido y se sabe a ciencia cierta que la labor no termina, pues el proceso perfectivo exige de calidad y continuidad de manera indefinida. Más allá del placer y del poder, las obras autorrealizativas dejan latente el deseo insaciable de autoconstrucción. $\mathrm{Y}$ aún en las condiciones más adversas, el hombre en proceso de autorrealización sortea de múltiples modos los obstáculos que halla en el camino hacia el cumplimiento del sentido existencial; es decir, que la persistencia es inherente a la felicidad. Igualmente, el hombre feliz sabe reconocer el llamado vocacional dentro de varias opciones que a la postre pueden resultar vanas; no se deja confundir, sabe que la abundancia es medio y no fin de la vida, entiende que la situación ambiental ofrece posibilidades de autorrealización para ser halladas y no limitaciones que encasillan el proceso perfectivo. En síntesis, es prudente y justo consigo mismo. 
Así, desde lo más propio del hombre es posible afirmar, al encuentro con Altarejos (1983), que la felicidad es la más preciada finalidad de la persona humana, pues en ella se conjugan la autorrealización como procesión dinámica subjetiva, la vocación como llamado pleno y el sentido existencial como horizonte claramente definido; por tal motivo hacia ella tienden todos los actos y tiene carácter autosuficiente. "Este anhelo insaciable de felicidad es el motor primero y la explicación última, la más comprensiva y honda de donde brotan todos nuestros comportamientos, como de la raíz brotan las ramas, las hojas y los frutos del árbol.” Jiménez, 1995: 165).

Mas, por la condición inconclusa del hombre, jamás se llega a alcanzar la perfección plenamente, la felicidad total nunca se da. En ese proceso perfectivo-feliz hay caídas, dificultades, tentaciones, desviaciones, aspectos susceptibles de ser superados en voluntad de sentido y práctica virtuosa, o de lo contrario, ser asimilados falsamente en voluntad de placer o poder, momentos que de ninguna manera son autorrealizaciones, ya porque la felicidad llega en la superación, ya porque la frustración existencial sobreviene en el vacío hedonista. Solamente es posible experimentar momentos de autorrealización que, convertidos en metas y a su vez en puntos de partida, conforman el proceso feliz. De manera que la felicidad no es perseguible, sólo es posible, grosso modo, vivir felices.

Subyace aquí un episodio sumamente importante en el desarrollo del presente artículo, es el momento de correlacionar la felicidad y el proceso educativo, porque si “.... la educación se nos aparece esencialmente referida a lo que hay más de humano en el hombre." (Millán, 1961: 65) y lo más humano del hombre reside en el proceso evolutivo hacia la búsqueda del bien supremo que es la felicidad, entonces la educación tiene como objeto la persona humana y su autorrealización.

Entiéndase que la perfección está constituida por el desarrollo máximo de todas las potencialidades humanas desde una perspectiva integral. "El per- fecto estado del hombre en tanto que hombre, que es el estado de virtud, no constituye nuestro último fin, sino el fin propio de la educación, el de la actividad educativa." (Millán, 1981: 53). En resumidas cuentas, la educación se constituye como una actuación netamente humana y con una finalidad perfectiva o feliz.

\section{La libertad como pilar educativo}

La libertad, al igual que la educación, es una categoría que pertenece exclusivamente a la humanidad. Primero porque requiere de la actitud razonada y segundo, porque al estar indisolublemente ligada al proceso educativo, implica el desarrollo personal, aspectos que solamente son posibles (por lo menos hasta lo hoy conocido) en el ser humano.

En efecto, desde lo razonativo, con primacía de reflexión y análisis, pasando por lo creativo y la toma de decisiones, la persona es el único ser en el universo capaz de experimentar la libertad, puesto que la insurrección, incluso contra sí mismo y el hecho de autorregularse, requieren, indudablemente, de la capacidad y el ejercicio de discernimiento.

Desde lo educativo y con atención al elemento autónomo de la persona, se entiende que la libertad es capacidad y práctica de autodeterminación desde la propia naturaleza antropológica, desde aquello que mueve al hombre a ser cultural y en la cultura misma, comprometiendo su integralidad (Mounier, 1993). De este modo la libertad se convierte en pilar educativo, en cuanto fundamenta la autorrealización, ya que ésta se hace palpable en el ejercicio autónomo de la voluntad de sentido, lo que se manifiesta en el esfuerzo máximo por el mejor cumplimiento de lo existencial, que en forma inicial se da en posibilidades de elección, decisión y aceptación.

La educación por ende no puede prescindir de la libertad. La búsqueda de la felicidad es ante todo un proceso continuo de decisiones, elecciones y aceptaciones, esto significa que la autorrealización humana esta fundamentada y mediada por actos 
autodeterminantes. Para llegar a ser hay que hacerse siendo, "se hace camino al andar"; sólo se conoce la libertad en la práctica libre. Significa que la libertad ha de ser factor permanente en todo el transcurso de la vida humana... si a esto le agregamos que la educación es un proceso vitalicio, por tanto libertad y educación van de la mano. No es posible la educación en ausencia de libertad y sin educación no hay libertad.

\section{Metas vs. medios}

La educación como acción humana con finalidad feliz, cobija todas las dimensiones del hombre como metas o fines intermedios y sus actuaciones como medios. Es de comprender que si la finalidad educativa es el estado perfecto del hombre en cuanto hombre y esto es impensable lejos de la integralidad, los fines intermedios que componen el desarrollo personal, han de ser observables y jerarquizados en cada una de las dimensiones humanas. Se trata de objetivos registrables en lo psicológico, lo físico y lo socio afectivo. Puede decirse que son estados sucesivos de maduración que inciden directamente en el desempeño humano hacía la autorrealización.

Pero la consecución de metas requiere del aspecto dinámico. Si el hombre es un organismo dotado de cinética y complejidad comportamental, es natural que su desarrollo personal se geste desde las actuaciones. De modo que el hombre se educa en el acto y actúa para educarse. Lo verdaderamente educativo está en el actuar y a su vez esto se fundamenta en la integralidad.

Pues bien, cuando se cambian los papeles y se confunden los fines con los medios, lo educativo deja de ser tal y se convierte en instruccionismo o adiestramiento, simple actividad informativa y amansadora enmarcada dentro del utilitarismo, situación que niega la felicidad, propiciando estados pasionales ciegos y mezquinos, propios de la pedagogía negra (Miller, 1985).

La instrucción está enmarcada dentro del cumplimiento de órdenes, esto se fundamenta a su vez en una información transmitida y repetida. El adiestramiento hace referencia a la adquisición de habilidades efectivas, en cuanto a haceres específicos, que llevadas a la práctica continua y sistemática, hacen del ejecutor un sujeto dotado de maña o pericia sobresaliente. El amaestramiento toca con la domesticación de los animales; pretende lograr de ellos comportamientos complejos e impropios al servicio del amaestrador.

En todos los casos se observa una relación de sometimiento, pues no es secreto que nadie se presta para ser instruido o adiestrado; menos aún, los animales se prestan al amaestramiento por iniciativa propia. Habiendo un alguien que instruye, adiestra o amaestra, y otro que obedece por medio de mecanismos condicionados, no cabe duda que la imposición y el dominio sean la constante. Ninguno de los tres momentos está relacionado con el desarrollo del ser humano, por estar matizados con lo impersonal. Lo grave del asunto está en quererlos homologar a lo humano, en cuanto a formación perfectiva, o sea, confundirlos con la educación; esto porque el proceso educativo no se reduce a formas de sometimiento.

En resumidas cuentas, ni instruccionismo, ni adiestramiento, ni amaestramiento, son situaciones educativas. El hombre que funciona bajo dispositivos represores, con la finalidad de atender órdenes y/o adquirir destrezas de cualquier tipo, para nada es educado. De igual manera puede hablarse acerca del animal amaestrado, con el agravante que la educabilidad es una característica exclusivamente humana.

Ahora es posible afirmar, que los contenidos, aprehendizajes y aprendizajes, en cuanto gestores de, y actuaciones mismas, se constituyen como medios educacionales y no como metas de la educación. Cada una de las sucesivas etapas del desarrollo personal humano, dadas en la pluridimensionalidad y básicas para el anhelo autorrealizativo, son fines del proceso educativo y no medios.

Luego, en lo que concierne al tiempo libre, el uso que se le dé a éste como actuación humana, 
está al servicio de la educación y no es fin de la misma. No es concebible entonces una reducción utilitarista de la educación para el uso del "tiempo libre", más bien se debe dar paso a un uso del "tiempo libre" en pro de la educación. "Por tanto, al menos desde la escuela, conviene educar para el empleo libre de un tiempo para uno mismo. Es un medio entre otros, pero medio esencial para individualizar y conducir a cada uno hacia la explotación de sus recursos singulares, extraídos de la totalidad de su ser". (Leif, 1992: 41).

\section{El tiempo}

En Heidegger, "La ontología es, en realidad, única y exclusivamente, aquella indagación que se ocupa del ser en cuanto ser, pero no como una mera entidad formal, ni como una existencia, sino como aquello que hace posibles las existencias." (Ferrater, 1990: 24-25). Es una teoría explicativa de la realidad desde su misma esencia. De hecho partimos del supuesto que afirma la inexistencia del tiempo, ya que no posee condiciones mínimas que le hagan posible una forma de estar en el universo, es decir que no se encuentra como un "ser ahi". Conviene ir hasta García Morente (1985) para aclarar de mejor manera lo ontológico del tiempo, ya desde las cosas, los objetos ideales y los valores.

Las cosas se ubican en el mundo real, tienen una forma de estar en él a partir de lo temporal, lo espacial y lo causal. Los objetos ideales, por el contrario, son atemporales, inespaciales y no causales. Los valores no logran una ubicación definida como objetos de razón, ni realidad, pues no se conservan como tales y tampoco afectan la estructura del ser real, por tal motivo, no son, no alcanzan la categoría de existencia, se constituyen entonces como grados de bueno y malo atendiendo en general al concepto de bien. La pregunta obligada es: ¿a cuál de estas esferas pertenece el tiempo? Respuesta: a ninguna.

En efecto, el tiempo no posee una forma real de estar en el cosmos, no es como vulgarmente se cree, que se trata de la conjugación entre otros seres reales como el sol, la lluvia, los vientos, etc., lo que en realidad es palpable y/o mensurable, son los efectos y funcionalidades de dichos seres, pero no hay evidencia de ese algo llamado tiempo.

Dentro de lo ideal, la estructura de las realidades no se ve afectada por el fenómeno temporal, es decir que no se constituye como relación, objeto matemático o esencia, a lo sumo llega a estar inserto dentro del sistema numérico como medida de la duración, pero no es número. Por último, no es posible referirse al tiempo como un valor, puesto que no se cataloga dentro del bien ni del mal, es neutro.

La duración es la pretendida congelación del movimiento, persigue estabilizar lo inestable, por lo tanto contiene globalidades cinéticas relacionadas entre sí, con sentido completo y susceptibles de medición por el mismo movimiento. De ahí que lo más cercano que puede estar el tiempo a la realidad es al lado de lo cinético, constituyéndose como medida de la duración del movimiento y siendo movimiento estandarizado; en consecuencia es multiforme, sucesivo y mutable. En este sentido el tiempo no existe, pues no tiene una conservación estable determinada, algo que Aristóteles afirmó en la física: "El tiempo no existe absolutamente, ha sido y ya no es, va a ser y todavía no es".

Ahora bien, desde la interioridad humana puede afirmase, atendiendo a Kant, que el tiempo no es concepto sino intuición; es la forma de las vivencias o percepciones internas, apreciación a la que llegó Santo Tomas con "el devenir del ahora, según la aprehensión concomitante de la razón"; es la sensación interna que se tiene de la duración de lo cinético. Sensación que indudablemente está relacionada con el interés humano, de ahí que determinados tiempos sean cortos o largos, rápidos o lentos, todo independientemente del reloj. Así tampoco existe el tiempo, porque no siendo producto lógico conceptual, no guarda estructura alguna de carácter estable y uniforme que le dé solidez.

En síntesis, el tiempo es inexistente, pues como condición de existencia real se niega dicha índole, menos encaja entre los objetos ideales, se reduce a la 
intuición en medio de la contingencia generada por el interés y la motivación humanas. "Por eso te voy a confiar un secreto: de aquí, de la casa de Ninguna Parte, en la calle de Jamás, viene el tiempo de todos los hombres." (Ende, 1992: 152).

\section{El tiempo libre}

Hay dos razones suficientes que justifican el fenómeno del tiempo libre como un absurdo, dígase que es algo hasta gracioso aunque rutinariamente suene

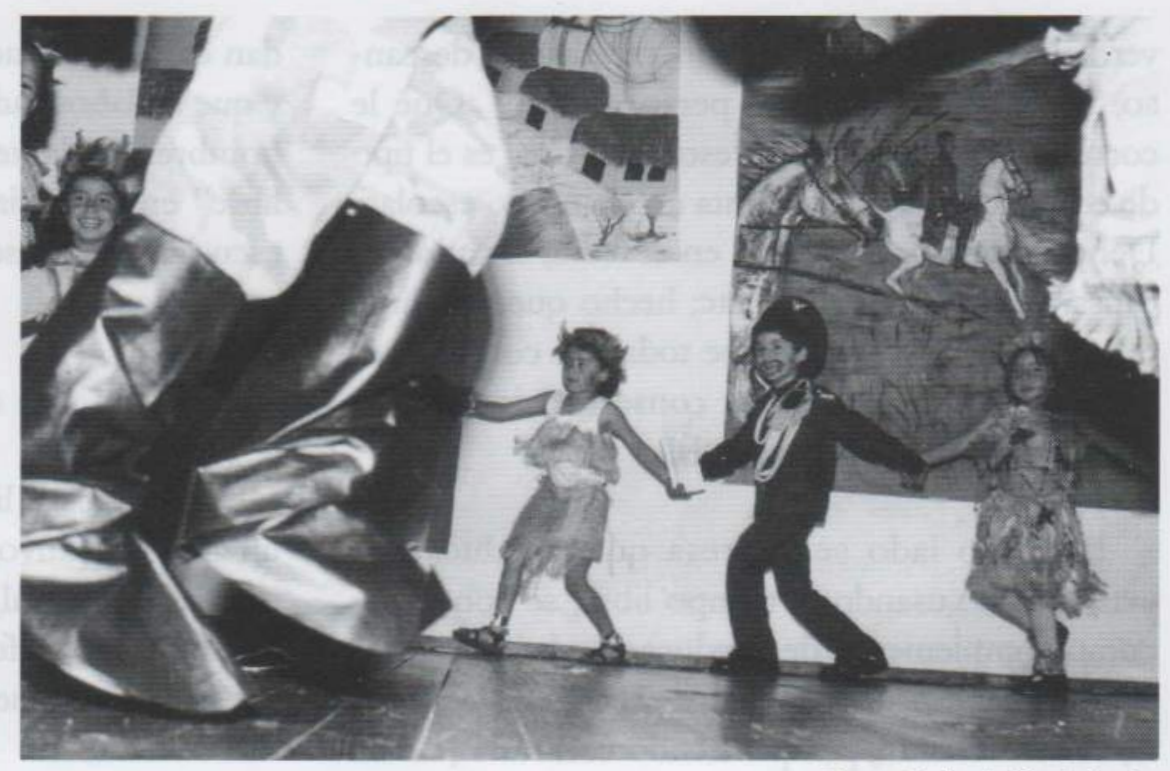

Por: Rafael Castañeda normal. Menos mal que lo aquí tratado es algo "anormal"... diferente.

Primero, lo inexistente no se rige bajo condiciones libres o represoras. La nada, siendo inmutable y uniforme, se halla sumergida en la indeterminación de lo eterno. Si el tiempo en realidad no es nada, entonces no puede ser libre ni cautivo. Segundo, en realidad, excepto el hombre, nada en el universo (hasta lo hoy conocido) es libre o preso. Si el tiempo no es humano, pues no razona y menos aún tiene vida espiritual. Careciendo de los dos elementos fundamentales para el ejercicio de la libertad, automáticamente queda por fuera de dicha categoría.

Otra cosa es lo que ocurre dentro del proceso cultural; para su identificación y manejo, la persona determina los fenómenos no humanos desde lo humano, lo que deja al descubierto un reflejo antropológico con respecto a la libertad, pero no la esencia del fenómeno determinado que en realidad se debate al azar. Así es como se ha llegado a hablar de caída libre, estilo libre, taxi libre, etc. Para el caso del "tiempo libre" puede decirse, que no existe como literalmente se presenta, sino que más bien se trata de un reflejo de la condición libre del hombre; lo que está en juego es la libertad a través de una actuación que dura y enmarca posibilidades de elección, aceptación y decisión.

\section{¿Y en la escuela?}

"La educación extraescolar es la que utiliza el tiempo libre, la recreación y el deporte como instrumentos fundamentales para la formación integral de los jóvenes y la niñez y la transformación del mundo juvenil con el propósito de que éste incorpore sus ideas, valores y su propio dinamismo interno al proceso de desarrollo de la nación. Esta educación complementa la brindada por la familia y la escuela..." (Ley 181, 1995, Art. 5).

"El aprovechamiento del tiempo libre: Es el uso constructivo que el ser humano hace de él, en beneficio de su enriquecimiento personal y el disfrute de la vida en forma individual o colectiva. Tiene como funciones básicas el descanso, la diversión, el complemento de la formación, la socialización, la creatividad, el desarrollo personal, la liberación en el trabajo y la recuperación sicobiológica." (Ley 181, 1995: Art. 5).

La gravedad del problema salta a la vista. Se evidencia una situación contradictoria sumamente nociva que merece atención única. Por un lado se entiende que la educación extraescolar es lo mejor que hay, en ella está implícito el tiempo libre como instrumento fundamental para la formación integral, conteniendo todo lo agradable e ideal de una 
verdadera educación (diversión, creatividad, descanso, liberación, desarrollo personal, etc.) ¿Qué le corresponde entonces a la escuela? ¿Cuál es el tipo de educación que se fomenta en el ámbito escolar? Debe ser una "educación" en el tedio, la rutina, el cansancio, la imposición, etc; hecho que a la larga no es educación, pues reúne todas las condiciones propias de la represión; en consecuencia, la labor educativa de la escuela es nula.

Por otro lado se expresa que la educación extraescolar, usando el tiempo libre, se constituye como complemento de la educación brindada por la familia y la escuela, lo cual, en el caso de la escuela, suena absurdo, porque siendo contrarias, no se complementan, se repelen. El complemento refuerza y/o completa la existencia de la unidad, de tal forma que es acertado decir, que el descanso no complementa el cansancio sino que lo anula. Entonces, escuela y tiempo libre, son antagónicos.

La contradicción es nociva porque desvirtúa el sentido educativo de la escuela y se cae en el reduccionismo informativo. El llamado uso del tiempo libre pasa a un segundo plano, y la escuela, desde su función tradicional, tiende únicamente a curricularizar lo extraescolar, desde el conocido instruccionismo. Esto indudablemente desvaloriza lo pedagógico. Todo confluye negativamente en el proceso educativo, siendo el niño quien más resulta perjudicado.

Según lo planteado, se entiende que, dentro o fuera de la escuela, el tiempo libre está conformado por todos aquellos espacios o actividades donde el alumno no se encuentra bajo el control del maestro. Se cree que los recreos, vacaciones, fines de semana, jornada contraria y eventualmente cuando el profesor no vigila, son momentos de libertad, creatividad, descanso, etc. Entonces, ¿cuál es la condición del alumno cuando está bajo la tutela del docente? No hay de otra, el educando está condicionado de forma heterónoma... está preso; situación que ocurre cuando los maestros enfocan su labor en la transmisión repeticionista basada en mecanismos de control y vigilancia, cuando olvi- dan que la libertad es un pilar educativo constante y que su labor radica en la formación personal del hombre. El planteamiento es sencillo: hay "tiempo libre" en ausencia del profesor... aún fuera de la escuela. Y la presencia del maestro denota estados represivos.

\section{Uso del tiempo libre}

La actuación libre del ser humano es de por sí un acto educativo, ya que se enrumba hacia la formación personal, que al expresar de Compayré (1920) es la perfección de la naturaleza humana, situación que puede darse hasta en las más mínimas formas.

Las situaciones que posibilitan el ejercicio de la libertad varían entre lo individual y lo colectivo, no se ciñen a determinados escenarios, se dan en la calle, el hogar, el bus, y a veces hasta en la escuela. Se presentan desde lo más simple y cotidiano, hasta lo azaroso. De igual modo, se dan por voluntad y responden a intereses y facilidades, no importa que se enmarquen dentro de algo programado, planeado o curricularizado, lo importante es asumirlas de manera autónoma, es decir, que ofrezcan modos de elección y decisión que posibiliten el crecimiento personal.

De manera que no existe nadie más indicado en decir como usar el "tiempo libre" que el propio interesado, ya que la felicidad es un asunto intransferible. "Positivamente, el tiempo para uno mismo y por sí mismo, es decir, el tiempo realmente libre, es el tiempo dominado, utilizado, vivido por decisión reflexionada individualmente y por voluntad personal de dominar los objetos libremente escogidos, para llenar un tiempo sustancial que no se pierde en el vacío. Tiempo sin otra servidumbre que la dependiente de uno mismo". (Leif, 1992: 42).

Desfasado es entonces querer imponer un recetario de actividades prefabricado a los educandos en horas extraescolares, es incongruente porque se aparta de los intereses personales de ellos, y concebido desde el razonado mundo de los 
adultos, persigue perpetuar el sistema vigente, dentro de la concepción tradicionista de "bueno y malo". En últimas, continúa la negación del hombre en pro del determinismo por miedo a la libertad. Se tiene una concepción lineal del tiempo, relacionada con el falso progreso, en lugar de dar relevancia a la actuación libre como fundamento en el desarrollo humano.

Luego hay que hacer es identificar todas las posibilidades de ese actuar libre y darles cumplimiento a carta cabal, lo cual es viable por medio de la aplicación de propuestas pedagógicas innovadoras y alejadas de lo tradicional repeticionista. Para efectos del tema, teniendo en cuenta que las posibilidades de actuación libre son infinitas y sin un ámbito definido, es necesario y viable clasificarlas de acuerdo con su centro de acción y origen:

\section{Desde la escuela:}

(Sin desconocerla como parte de la comunidad) se ubican todas aquellas actividades que pueden ser originadas, promovidas y ejecutadas desde el centro educativo, (sin ceñirse exclusivamente a él), con la participación directa del personal docente. Tenemos:

- Formas cotidianas de lo escolar (refiérese específicamente al cambio de la rutina escolar por formas de encuentro verdaderamente educativas entre maestros y alumnos. Cambio que, lógicamente, ha de partir en primera medida del profesor).

- Actividades en el medio social y geográfico (comprende todo aquello que se puede realizar desde los límites de la escuela, físicamente hablando, hacia fuera de manera indeterminada; visitas a parques y museos, caminatas, campamentos, asistencia a espectáculos, bibliotecas, clubes, intercambios deportivos, etc).

- Aprendizaje y manifestación cultural (se incluye aquí todo lo que tiene que ver con las formas de vida propias de la sociedad, folclóricas o no, y que pueden darse programadamente o no, pero cuya relación humana está mediada por el actuar libre; cursos, capacitaciones, expresión artística y deportiva, etc.).

\section{Desde la comunidad:}

Comprende todas las actuaciones que pueden ser promovidas y ejecutadas fuera del centro educativo y cuentan con la participación directa de las personas pertenecientes a la comunidad que no son docentes de la institución.

- Actividades en familia

- Actividades en medio social y geográfico

- Aprendizaje y manifestación cultural.

\section{Propuestas pedagógicas}

En última instancia, para consolidar respuesta al decreto 1860 en su artículo 14, numeral 6, cabe anotar que la pedagogía, como saber puro práctico de la educación, tiene su acción en el estudio sistemático de ésta, en cuanto que realizable y en realización. Al intentar descubrir, analizar y cuestionar el hecho educativo, la pedagogía se convierte en teoría de la educación. "Existe, pues, una ciencia de la educación, ciencia práctica, de aplicación, que tiene sus principios y sus leyes, que prueba su vitalidad por gran número de publicaciones, tanto en Francia como en el extranjero, y que tiene su nombre, aunque haya todavía quien duda en dárselo: la pedagogía". (Compayré, 1920: 11). Posición hasta hoy defendida por cualquier pedagogo sistemático.

Los resultados de la teorización educativa que suenan como alternativas de aplicación, se denominan propuestas pedagógicas, mas no son acciones de la pedagogía, pues se ciñen sólo al constructo teórico de la educación. Para efectos del tema tratado, las propuestas pedagógicas son:

\section{- Alternativa de cambio}

La escuela y la comunidad deben reformular su actuar educativo. Es necesario abolir la concepción reduccionista de la educación como una práctica instruccionista basada en el transmisionismo repeticionista, hay que abordarla desde lo humano como un proceso constante de autorrealización personal basado en el ejercicio de la libertad. 
Urgente es que la escuela se transforme en un espacio de libre actuación. Esto se logra en primera medida, con una actitud de cambio por parte de directivos y maestros, sin miedos y sin tabúes, reflexionando continuamente sobre la labor efectuada a diario; el resultado debe ser un replanteamiento firme de los conceptos, métodos, contenidos, objetivos, y una expresión creativa en la lucha por la libertad que se hace interminable (Mounier, 1993). Porque la libertad no es un ideal sino una experiencia esencial en la vida del hombre, hay que hacerse libres liberándose. 'Tenemos que hacer algo, una escuela donde sea peligroso controvertir no es escuela. Donde no exista un espacio para la diferencia, tampoco lo es. Una escuela que se niega la posibilidad de otros aromas, saborear otros menús, escuchar otras sinfonías y palpar otros cielos está condenada a que su luz se extinga." (Olave, 1997: 11) La cotidianidad de la escuela será diferente cuando la comunidad escolar conciba la educación más allá del tradicionalismo vigente.

\section{- La Educación es responsabilidad de todos}

Se observa como parte relevante en la alternativa de cambio, el compromiso que la comunidad educativa debe tener con la educación. Esta, como proceso constante y cotidiano, no se ciñe únicamente al medio escolar. De cualquier manera, al hombre educarse en comunidad y por comunicación, se pone de manifiesto, que cualquier tipo de relación interpersonal, puede ser un acto educativo, entonces los profesores dejan de ser los únicos agentes con potencialidad educativa. Se trata de llegar a asumir el proceso educativo como un hecho globalmente comunal en el que cada persona tiene velas en el asunto sin ser necesariamente profesor(a). Es así, que la comunidad educativa debe reconocer, aceptar y asumir la responsabilidad que le compete en la educación extraescolar, máxime cuando una ínfima parte de sus miembros están en la escuela durante un reducido lapso de tiempo al día (6 horas de las 24).

La familia como primer agente socializador, con función articulativa entre lo público y lo privado, posee gran responsabilidad en el proceso educati- vo extraescolar. Cuando el niño ingresa a la escuela lleva consigo un bagaje cultural aprendido en el seno familiar por espacio de 5 a 6 años, bagaje que influye seriamente en los procesos de desarrollo sicomotriz y socio afectivo.

Con respecto a la acción educativa de la familia, la ley general de educación reconoce y reglamenta dicha acción: "la familia: a la familia como núcleo fundamental de la sociedad y primer responsable de la educación de los hijos, hasta la mayoría de edad o cuando ocurra otra clase o forma de emancipación, le corresponde: [...]

d- Buscar y recibir orientación sobre la educación de los hijos. [...]

f- Contribuir solidariamente con la institución educativa para la formación de sus hijos, y

g-Educar a sus hijos y proporcionarles en el hogar el ambiente adecuado para su desarrollo integral". (Ley 115, 1994, Art. 7).

\section{- Priorizar la actividad física y el juego}

Las actividades de orden físico son primordiales en el proceso educativo por razones de tipo integral; porque si lo educable es el hombre mismo, como unidad indisoluble y dinámica de cuerpo, mente y espíritu, lo cinético es entonces expresión palpable de lo humano.

Es a través del movimiento que se propicia la génesis de la conciencia y su posterior desarrollo. "La conciencia es un tejido viviente secretado al compás de los movimientos corporales, al igual que una araña secreta la tela que actuando como espacio auxiliar potencializa sus relaciones con el mundo. En esta labor artesanal por medio de la cual el cuerpo teje la conciencia, se conjugan diversos tipos de puntadas que dan lugar a diferentes formas de simbolización y pensamiento, constituyentes indispensables del fenómeno mental humano." (Restrepo, 1994: 95-96). El cuerpo entonces constituye la presencia misma del hombre en el universo y es medio por naturaleza al servicio de la construcción del conocimiento. 
Por otra parte, como organismo biológico, la constitución del propio cuerpo desarrollado es el principio de individuación en la formación personal. El desarrollo biológico es determinante en la maduración y desempeño motriz, influye también en las formas y dimensiones corporales, lo que ayuda a forjarse una imagen de sí mismo en el plano físico, reconociendo capacidades y limitaciones. De manera que en lo material, la apropiación de sí se da en lo corporal, apropiación que tiene efectos en todo lo humano.

Cuerpo y movimiento también son comunicación, por medio de ellos se expresan y reciben sentimientos, ya por la palabra condicionada por el tono de voz, ya en los ademanes y gestos, en la mirada, en los roces y hasta en lo accesorio, aspectos que tocados desde el trato específico por medio del cual un yo se encuentra a sí mismo a través de un tú, son a ciencia cierta elementos comunicativos. Pero el cuerpo sólo es potencialidad expresiva, cultural y personal, en el movimiento; el hombre queda reducido a despojo humano cuando la muerte colma el cuerpo y hurta el movimiento. Cuando el cuerpo se limita en lo motriz de forma represiva, también se limita la autorrealización humana.

Y cuando de niños se trata, el juego es la actividad educativa por excelencia: "Está visto y comprobado que el juego libre es vital para el sano desarrollo físico y emocional de los niños. Es jugando como los niños ejercitan una serie de actividades que deben dominar para convertirse en adultos competentes. El juego es una experiencia multidimencional que involucra a todo el equipo perceptual, motor sensorial y cognitivo de los niños; es decisiva en su desarrollo físico y neurológico.

Además, a través de los juegos, los niños exploran sus ambientes, perfeccionan sus habilidades sociales y dan rienda suelta a su creatividad y su imaginación. Los juegos les dan oportunidad de ensayar roles adultos y jugando a la casa, al colegio o al médico exploran y pueden comprender el mundo de los mayores.

Adicionalmente, los niños que tienen oportunidades de jugar libremente con sus compañeros desarrollan mejores relaciones interpersonales, son más populares y tienen más capacidad de liderazgo, porque han aprendido a respetar turnos, negociar, resolver diferencias con otros y trabajar en grupo". (Marulanda, 1997, 5B).

Es importante entonces propiciar, en y desde la escuela, actividades físicas con carácter lúdico en todo el sentido de la frase, trátese de programas recreativos, de formación deportiva, de aprendizaje cultural o actividades casuales. No sobra decir que la educación física está llamada a cumplir un papel de vital importancia en todo lo planteado.

\section{Bibliografia}

ARISTÓTELES. (1994). Ética nicomaquea. Bogotá. Gráficas Modernas.

ALTAREJOS, Francisco. (1983). Educación y felicidad. Pamplona, España. Universidad de Navarra. Bouret.

COMPAYRE, Gabriel. (1920). Curso de pedagogia. París.

ENDE, Michael, (1992). Momo. Madrid. Alfaguara.

FRANKL, Víctor. (1977). La presencia ignorada de Dios. Barcelona, España. Herder.

FERRATER MORA, José. (1990). Diccionario filosófico. Buenos Aires. Suramericana.
FREIRE, Paulo. (1986). Pedagogía del oprimido. México. Siglo XXI.

GALLEGO BADILLO, Rómulo. (1990). Saber pedagógico. Bogotá. Magisterio.

GARCÍA HOZ, Víctor. (1986). Educación personalizada. Madrid. Rialp

GARCÍA MORENTE, Manuel. (1985). Lecciones preliminares de filosofia. Buenos Aires. Losada.

GUTIERREZ, Francisco. (1984). Educación como praxis politica. México. Siglo XXI. 
HEIDEGGER, Martín. (1993). El ser y el tiempo. Bogotá. Fondo de Cultura Económica.

IANFRANCESCO, Giovanni. (1995). Propuesta del modelo curricular personalizado. En: Actualidad educativa (septiembre-diciembre). No. 9-10, p. 68-76. Santa Fe de Bogotá. Libros y libres.

JIMENEZ C., Álvaro. (1995). Triunfar como persona: el arte de crecer. Bogotá. CEJA, Centro Editorial Javeriano.

LEIF, Joseph. (1992). Tiempo libre y tiempo para uno mismo: un reto educativo y cultural. Madrid. Narcea.

MARULANDA, Ángela. (1997). Los niños ya no pueden jugar. En: El Tiempo (enero 27). p. 5B. Bogotá.

MATURANA, Humberto. (1996. El sentido de lo bumano. Santiago de Chile. Dolmen.

MILLAN, Puelles. (1981). La formación de la personalidad bumana. Madrid. Rialp.
MILLER, Alice. (1985). Por tu propio bien. Barcelona, España. Tusques.

MOUNIER, Emmanuel. (1993). El personalismo. Bogotá. Editorial El Búho.

OLAVE, Marco Antonio. (1997). Cotidianidad y escuela: ¡Cómo me pesas! En: Magazín Aula Urbana (septiembre-octubre). $\mathrm{N}^{\circ} 2$, p.11. Bogotá. IDEP.

RESTREPO, Luis Carlos. (1994). La trampa de la razón. Bogotá. Retina.

VEGA Delgado, José. (1974). Una explicación metafisica del tiempo. Cuenca, Ecuador. Universidad Católica.

ZEZINHO, P.. (1995). La vocación de cada uno. Bogotá. Taller San Pablo. 